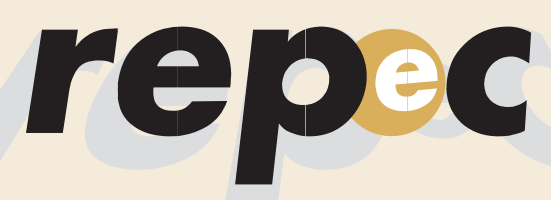

REPeC, Brasília, v. 8, n. 3, art. 6, p. 326-343, jul./set. 2014 Disponível online em www.repec.org.br DOI: http://dx.doi.org/10.17524/repec.v8i3.1079

\title{
Quinze Anos de Produção Acadêmica do Tema Contabilidade Internacional: uma Análise Bibliométrica em Periódicos Brasileiros
}

\begin{abstract}
Resumo
A Contabilidade Internacional é ampla no que se refere às suas práticas, princípios e normas, pois ela é oriunda de um mercado de capitais que evidencia uma diversidade de negócios que influencia no ambiente organizacional onde as empresas se inserem. O objetivo deste artigo foi investigar qual é o perfil e o crescimento, no período de 1999 a 2013, das publicações acadêmicas sobre Contabilidade Internacional em periódicos brasileiros classificados com notas A1, A2, B1 e B2, pela Qualis Capes das áreas de Administração, Contabilidade e Turismo (triênio 2010-2012). Foram identificados 142 artigos e analisados, utilizando-se as técnicas de análise bibliométrica e de rede social. Os principais resultados foram: a Revista Contabilidade \& Finanças e a Revista Universo Contábil foram as que mais publicaram artigos; o número de publicações sobre o tema em investigação teve maior crescimento a partir do ano de 2007; houve predominância de artigos publicados em parceria, sobretudo com dois e três autores; a Universidade de São Paulo (USP) foi a IES mais profícua; constatou-se uma baixa densidade e uma alta centralidade de grau; os temas Evidenciação das Informações, Harmonização Contábil, Convergência Contábil, Disclosure e US GAAP foram os mais publicados.
\end{abstract}

Palavras-chave: Contabilidade internacional; Produção acadêmica; Análise bibliométrica.
Henrique César Melo Ribeiro Doutor em Administração (Uninove$\mathrm{SP})$, professor do Mestrado profissional em Administração/Gestão de Esportes (Uninove-SP) e professor da Faculdade Maurício de Nassau. Contato: BR-343, km 7,5, S/N, Floriópolis, Parnaíba, PI, Brasil, CEP: 64.202-260.

E-mail: hcmribeiro@hotmail.com 


\section{Introdução}

A Contabilidade Internacional é a ciência que estuda, em especial, as causas das diferenças internacionais no Financial Reporting entre as nações e os problemas mais relevantes aos negócios internacionais (Ikuno, Niyama, Santana \& Botelho, 2012). Realça-se que o tema é bem abrangente, contudo, ainda em evolução no âmbito acadêmico nacional (Ribeiro, 2013b). Entretanto, ainda não foram evidenciadas opiniões robustas a respeito do referido assunto (Niyama, Mendonça \& Aquino, 2007). Diante disso, é preponderante alavancar o conhecimento sobre o tema, mediante o fomento e a disseminação da estrutura intelectual de suas publicações acadêmicas.

E uma maneira de se alavancar, fomentar e socializar o conhecimento de um determinado tema é a análise bibliométrica (Ikuno, 2011) e de rede social (Ribeiro, 2013a). São encontradas algumas pesquisas bibliométricas sobre contabilidade internacional: Cunha, Rausch e Cunha (2010), Tavares, Lopes e Ribeiro (2010), Coelho, Niyama e Rodrigues (2011), Ikuno (2011), Quintana e Fernandes (2011), Botelho (2012) e Ikuno et al. (2012). Entretanto, nenhuma dessas pesquisas utilizou a análise de redes sociais. Além disso, esses estudos não alcançaram a atualização do triênio da Capes (2014), ou seja, o atual triênio (2010-2012). Outra observação é que esses trabalhos não analisaram conjuntamente as mais importantes revistas da grande área da Capes (2014) de Administração, Contabilidade e Turismo. Portanto, diante dos fatos, ressalta-se a oportunidade de contribuição para expandir o conhecimento adquirido pelas pesquisas bibliométricas realizadas e publicadas anteriormente sobre contabilidade internacional.

Diante do panorama, define-se a seguir o objetivo deste estudo, que é investigar qual o perfil e o crescimento, no período de 1999 a 2013, das publicações acadêmicas sobre Contabilidade Internacional em periódicos brasileiros classificados com notas A1, A2, B1 e B2, pela Qualis Capes das áreas de Administração, Contabilidade e Turismo (triênio 2010-2012).

Justifica-se esta pesquisa pela importância que o tema Contabilidade Internacional tem para a grande área contábil. Mesmo que já tenham sido realizados e publicados outros estudos bibliométricos, este contribuirá para o alargamento, fomento, aperfeiçoamento e atualização de trabalhos feitos anteriormente.

Este estudo buscará contribuir também para otimizar, disseminar, socializar e agregar conhecimento para a estrutura intelectual do tema Contabilidade Internacional para a literatura acadêmica nacional, influenciando no surgimento de novos estudiosos sobre o assunto e consequentemente no aumento de novos grupos de estudos, acarretando no incremento das redes de coautoria, redes das IES, alavancando, promovendo e socializando, assim, o tema propriamente dito e as temáticas derivadas desse assunto nos futuros artigos acadêmicos que serão publicados em congressos, seminários e em periódicos nacionais e internacionais.

\section{Fundamentação teórica}

\subsection{Contabilidade Internacional}

A Contabilidade Internacional é bem diversa no que tange as suas práticas, pois ela é oriunda de um mercado corporativo mundial que contempla uma variedade de negócios que impacta no ambiente organizacional onde as empresas estão inseridas (Botelho, Oliveira, Resende, \& Ogliari, 2002). Sendo assim, a Contabilidade Internacional é preponderante para medir a participação real das empresas em meio a esse cenário.

Outro foco importante sobre a Contabilidade Internacional é a distinção entre os termos "harmonização" e "convergência" (Lemes \& Carvalho, 2009). A harmonização tem sinônimo de aproximação (Niyama, Botelho, Corrêa \& Santana, 2008) enquanto a convergência é o movimento voltado para a paridade entre as escolhas das alternativas de tratamento dos dados contábeis (Ponte, De Luca, Sousa \& Ca- 
valcante, 2011). Diante disso, pode-se entender que a própria convergência é o processo de obtenção da harmonização dos padrões contábeis (Lemes \& Carvalho, 2009).

Em suma, a harmonização contábil (convergência) (Vaz, Gonlaves, Niyama \& Gonçalves, 2010) é um processo pelo qual várias nações, em comum acordo, fazem mudanças nos seus sistemas e normas contábeis, fazendo com que eles se tornem ajustados, continuando a respeitar as características inerentes de cada país (Silva, Madeira \& Assis, 2004). Em relação às normas contábeis internacionais, realçam-se as International Financial Reporting Standards (IFRS) (Oliveira \& Lemes, 2011) emitidas pelo International Accounting Standards Board (IASB) (Carmo, Ribeiro \& Carvalho, 2011) e os Generally Accepted Accounting Principles in the United States (US-GAAP) (Hajj \& Lisboa, 2001) emitidas pelo Financial Accounting Standards Board (FASB) (Lemes \& Carvalho, 2009).

Após anos de deliberação, a Lei n. ${ }^{\circ} 11.638 / 07$ e a Lei n. ${ }^{\circ}$ 11.941/09 (MP 449/08) determinaram a harmonização contábil com as IFRS, alinhando o Brasil ao processo de internacionalização da contabilidade (Santos \& Calixto, 2010). Essas leis foram necessárias devido às mudanças ocorridas no mercado de capitais do Brasil e, consequentemente, pela relação das organizações nacionais com as estrangeiras, tornando possível uma aproximação com as normas internacionais (Squena \& Pasuch, 2010).

É salutar o domínio que o conhecimento sobre as Normas Contábeis Internacionais vem atingindo na área contábil nacional, principalmente, depois da implementação da Lei n. ${ }^{\circ}$ 11.638/07 (Miranda, Santos, Casa Nova \& Cornacchione Jr., 2013), impactando nas empresas de grande porte no Brasil (Santos, Lima, Freitas \& Lima, 2011). E esta autoridade pode ser vista por meio de pesquisas bibliométricas já realizadas que realçam e exploram o conhecimento científico sobre o tema Contabilidade Internacional.

Cunha, Rausch e Cunha (2010) identificaram as abordagens metodológicas e técnicas de pesquisa utilizadas nos artigos científicos sobre Contabilidade Internacional publicados no Congresso de Controladoria e Contabilidade USP e Revista de Contabilidade \& Finanças USP. Concluíram que a abordagem metodológica mais utilizada pelos pesquisadores da área foi a sistêmica/estruturalista. A técnica de pesquisa mais utilizada foi a análise bibliográfica.

Tavares et al. (2010) identificaram o perfil da pesquisa na área de Contabilidade Internacional nas dissertações e teses brasileiras entre 1999 e 2008. Como resultado, os autores constataram que o perfil da pesquisa em Contabilidade Internacional é caracterizado predominantemente por estudos comparativos, sendo esses estudos teórico-empíricos, com ênfase na análise da pesquisa documental. A abordagem metodológica mais comumente utilizada é o empirismo, com uma postura teórica positivista.

Coelho, Niyama e Rodrigues (2011) analisaram a situação da informação contábil com a adoção do IFRS, isto é, os autores verificaram os achados e resultados de artigos publicados em periódicos internacionais que tratam do impacto dos IFRS sobre a qualidade da informação contábil. Os resultados evidenciaram que: a maioria dos artigos tratava de fato do impacto do IFRS sobre a qualidade da informação contábil, sendo a transparência a variável mais utilizada nos estudos para mensurar a qualidade da informação. Concluiu-se que o impacto do IFRS de maneira geral pode ser qualificado como positivo.

Ikuno (2011) caracterizou a produção científica em Contabilidade Internacional publicada nos periódicos internacionais de língua inglesa de 2000 a 2010. Os principais resultados foram: predominância de artigos publicados em parceria; os Estados Unidos (EUA), Reino Unido e Austrália, destacaram-se nas pesquisas sobre Contabilidade Internacional no que tange à quantidade de Instituições de Ensino Superior (IES) vinculadas a eles.

Quintana e Fernandes (2011) verificaram a produção científica específica ou análoga sobre harmonização contábil internacional, na Revista Contabilidade e Finanças da Universidade de São Paulo (SP), no período de 2005 a 2011. Os pesquisadores concluíram que o número de trabalhos desenvolvidos sobre o tema Harmonização Contábil, na revista, no período de 2005 a 2011, é ainda limitado e, consequentemente, notaram que a discussão da harmonização ou convergência contábil está sem dúvida em estágio inicial e se faz urgente a publicação de mais estudos neste tema.

Botelho (2012) analisou a produção científica em Contabilidade Internacional identificadas nos estudos de âmbito internacional, no período compreendido entre 2001 e 2010. Com isso, 100 artigos cien- 
tíficos foram identificados, oriundos de 10 periódicos internacionais. Os principais resultados foram: os EUA, Reino Unido e Austrália destacaram-se por terem o maior número de instituições acadêmicas vinculadas, respectivamente, a elas.

Ikuno et al. (2012) identificaram os principais temas enfocados na produção científica relativos ao Financial Reporting nos principais periódicos internacionais entre os anos de 2000 e 2009. A principal temática identificada foram as diferenças internacionais e a implicação no Financial Reporting. Logo em seguida vieram: a mensuração da convergência e o impacto da adoção das IAS/IFRS. Já a maior concentração de artigos nos anos de 2006 e 2007 pode estar relacionada ao aumento das bases de dados resultantes da adoção obrigatória das IFRS pela União Europeia, em 2005.

Contemplou-se assim um panorama sobre o tema Contabilidade Internacional e a evidenciação de pesquisas biblimétricas sobre este assunto, revelando algumas nuances do conhecimento intelectual, mediante artigos publicados sobre a temática Contabilidade. Contudo, essas pesquisas anteriormente citadas não realçaram outros atributos que porventura são preponderantes para o melhor entendimento $\mathrm{e}$ conhecimento do assunto em questão.

Nesse panorama, este estudo tem esse objetivo e com isso abordará a mensuração, análise e discussão das seguintes variáveis: periódicos nacionais que se destacam na publicação do tema em investigação, crescimento das pesquisas em contabilidade internacional, autoria, autores, redes de coautoria, IES, rede das IES, rede dos estados e países em conjuntos, palavras-chave e temas abordados. Salienta-se também que essas variáveis foram analisadas utilizando o atual triênio (2010-2012) da Capes (2014), em 59 periódicos da área de Administração, Contabilidade e Turismo, somando 142 artigos publicados.

\section{Procedimentos metodológicos}

O objetivo deste estudo foi de investigar qual o perfil e o crescimento, no período de 1999 a 2013, das publicações acadêmicas sobre Contabilidade Internacional em periódicos brasileiros classificados com notas A1, A2, B1 e B2, pela Qualis/Capes das áreas de Administração, Contabilidade e Turismo (triênio 2010-2012).

Para tanto, utilizaram-se técnicas de análise bibliométrica (Ikuno, 2011) e de rede social (Ribeiro, 2013a). A bibliometria é um conjunto de métodos de estudo da área das Ciências da Informação que usa técnicas de análise quantitativa de dados, para investigar a estrutura de um campo científico e também como técnica para se analisar o comportamento dos autores em suas decisões na criação do conhecimento (Leite Filho, 2008). Já a rede social é entendida como as conexões entre atores, ou seja, é a medida do número de laços que um ator possui com outros atores (Nascimento \& Beuren, 2011).

Salienta-se que a bibliometria desenvolveu-se por meio da preparação de leis empíricas sobre o comportamento da literatura acadêmica (Egghe, 2005). Nesse contexto, é preponderante apreciar as três leis básicas da bibliometria, para o melhor entendimento dos resultados desta pesquisa. Essas leis são nativas respectivamente de três autores que se destacam por suas importantes descobertas, são eles: Bradford, Zipf e Lotka, assim sendo, as mais frequentemente utilizadas e catalogadas à produtividade acadêmica (Egghe, 2005).

A Lei de Lotka observa os padrões de produtividade dos autores em determinada área do conhecimento (Leite Filho, 2008). Já a Lei de Bradford mensura a produtividade das revistas e sua relação com determinados temas da literatura acadêmica, evidenciando assim o núcleo de periódicos que evidenciam mais este assunto (Cardoso, Mendonça, Riccio \& Sakata, 2005). E a Lei de Zipf mensura a ocorrência de palavras-chave no texto, sendo que a frequência dessas palavras-chave dão embasamento para se saber qual tema é enfatizado neste texto (De Luca, Gomes, Corrêa \& Domingos, 2011).

No que tange à análise de redes sociais, realçam-se os atributos dos nós, laços, densidade e centralidade (Cruz, Espejo, Costa \& Almeida, 2011). No que tange à densidade, ela representa um índice do potencial de comunicação entre os atores da rede, contribuindo identificar a quantidade e os tipos de in- 
formações que podem ser trocadas entre eles (Guimarães, Gomes, Odelius, Zancan \& Corradi, 2009). Já a centralidade é uma das propriedades de redes mais utilizadas, pois ela enfatiza aspectos relacionados à importância ou visibilidade de um ator em uma rede social (Cruz et al., 2011). Desta, realça-se a centralidade de grau (degree) que é definida simplesmente pelo número de laços adjacentes de um ator em relação aos outros que compõem essa rede (Rossoni \& Guarido Filho, 2009).

Para se desenvolver a pesquisa bibliométrica e de rede social, foram escolhidos as revistas brasileiras classificadas com a nota A1, A2, B1 e B2 pela Qualis/Capes das áreas de Administração, Contabilidade e Turismo (triênio 2010-2012). Estes representam os extratos superiores de avaliação. Diante disso, chegou-se à relação relacionada no Tabela 1 .

Tabela 1

Classificação dos periódicos, triênio (2010-2012)

\begin{tabular}{|c|c|c|}
\hline Revista & ISSN & Nota \\
\hline Brazilian Administration Review & $1807-7692$ & A2 \\
\hline Brazilian Business Review & $1807-734 X$ & $\mathrm{~A} 2$ \\
\hline Gestão \& Produção & 1806-9649 ou 0104-530X & A2 \\
\hline RAC Eletrônica & $1981-5700$ & $\mathrm{~A} 2$ \\
\hline Revista de Administração Contemporânea & $1415-6555$ ou $1982-7849$ & $\mathrm{~A} 2$ \\
\hline RAE Eletrônica & $1676-5648$ & A2 \\
\hline Revista de Administração de Empresas & 0034-7590 ou 2178-938X & A2 \\
\hline RAUSP-e & $1983-7488$ & A2 \\
\hline Revista Brasileira de Economia & 0034-7140 & $\mathrm{A} 2$ \\
\hline Revista Contabilidade \& Finanças & 1519-7077 ou $1808-057 X$ & $\mathrm{~A} 2$ \\
\hline Revista de Administração da USP & 0080-2107 ou 1984-6142 & $\mathrm{A} 2$ \\
\hline Revista de Administração Pública & 0034-7612 & $\mathrm{A} 2$ \\
\hline Revista Base & 1984-8196 ou 1807-054X & B1 \\
\hline Cadernos EBAPE.BR & $1679-3951$ & B1 \\
\hline Contabilidade Vista \& Revista & 0103-734X & B1 \\
\hline Contexto Internacional & $0102-8529$ & B1 \\
\hline Economia Aplicada & $1413-8050$ & B1 \\
\hline Economia e Sociedade & 0104-0618 & B1 \\
\hline Economia Global e Gestão & 0873-7444 & B1 \\
\hline Estudos Econômicos & $0101-4161$ & B1 \\
\hline Faces : Revista de Administração & $1517-8900$ ou $1984-6975$ & B1 \\
\hline Gestão \& Regionalidade & $1808-5792$ ou $2176-5308$ & B1 \\
\hline Produção & $1980-5411$ ou $0103-6513$ & B1 \\
\hline Nova Economia & $0103-6351$ & B1 \\
\hline Revista de Administração e Inovação & $1809-2039$ & B1 \\
\hline Revista de Administração Mackenzie & $1518-6776$ ou $1678-6971$ & B1 \\
\hline Revista Eletrônica de Administração & $1413-2311$ ou $1980-4164$ & B1 \\
\hline Revista Brasileira de Finanças & $1679-0731$ ou $1984-5146$ & B1 \\
\hline Revista Brasileira de Gestão de Negócios & 1983-0807 ou 1806-4892 & B1 \\
\hline Revista Contemporânea de Contabilidade & $2175-8069$ ou $1807-1821$ & B1 \\
\hline Revista de Administração da UFSM & $1983-4659$ & B1 \\
\hline Revista de administração da Unimep & $1679-5350$ & B1 \\
\hline Revista de Ciências da Administração & 2175-8077 ou $1516-3865$ & B1 \\
\hline Revista de Contabilidade e Organizações & $1982-6486$ & B1 \\
\hline
\end{tabular}




\begin{tabular}{|c|c|c|}
\hline Revista & ISSN & Nota \\
\hline Revista de Economia Contemporânea & $1415-9848$ & B1 \\
\hline Revista Universo Contábil & $1809-3337$ & B1 \\
\hline Contextus & $1678-2089$ & B2 \\
\hline Enfoque: Reflexão Contábil & $1517-9087$ & B2 \\
\hline Gestão \& Planejamento & $2178-8030$ & B2 \\
\hline Gestão \& Sociedade & $1980-5756$ & B2 \\
\hline Internext & $1980-4865$ & B2 \\
\hline Organizações em Contexto & $1809-1040$ ou $1982-8756$ & B2 \\
\hline Perspectivas Contemporâneas & 1980-0193 & B2 \\
\hline Pretexto & $1517-672 X$ ou $1984-6983$ & B2 \\
\hline Revista de Administração, Contabilidade e Economia & $1678-6483$ ou $2179-4936$ & B2 \\
\hline Revista Brasileira de Estratégia & $1983-8484$ & B2 \\
\hline Revista Eletrônica de Ciência Administrativa & $1677-7387$ & B2 \\
\hline Revista de Gestão da USP & $2177-8736$ ou $1809-2276$ & B2 \\
\hline Revista Alcance & 1983-716X & B2 \\
\hline Revista Ambiente Contábil & 2176-9036 & B2 \\
\hline Revista de Educação e Pesquisa em Contabilidade & $1981-8610$ & B2 \\
\hline Revista Economia \& Gestão & 1984-6606 & B2 \\
\hline Revista Iberoamericana de Estratégia & 2176-0756 & B2 \\
\hline Revista Pensamento Contemporâneo em Administração & $1982-2596$ & B2 \\
\hline Revista de Gestão Organizacional & $1806-6720$ ou $1983-6635$ & B2 \\
\hline Revista de Gestão Social e Ambiental & $1981-982 X$ & B2 \\
\hline Sociedade, Contabilidade e Gestão & $1982-7342$ & B2 \\
\hline
\end{tabular}

Fonte: Capes (2014)

O Tabela 1 contempla, portanto, que neste estudo foram analisados 59 periódicos científicos nacionais. A coleta de dados foi realizada buscando, nessas revistas, artigos publicados entre 1999 a 2013. Cada uma das revistas relacionadas no Tabela 1 passou por processo de busca de papers que correspondessem ao tema em investigação. Em todos os artigos, a disponibilidade deles foi em meio eletrônico. Diante disso, os manuscritos foram acessados diretamente de seus respectivos sites, sendo que a busca foi feita de maneira minuciosa, para, com isso, encontrar todos os artigos que tivessem as palavras-chave: Contabilidade Internacional e ou International Accounting, no título, no resumo ou nas palavras-chave de cada artigo publicado.

As palavras-chave não foram pesquisadas de maneira simultânea, para que fossem selecionadas todas as publicações que tivessem ao menos uma das palavras-chave anteriormente evidenciadas. A coleta de dados retornou 142 artigos que foram analisados de maneira quantitativa, conforme as seguintes variáveis: (I) periódicos e os de maior destaque; (II) crescimento das pesquisas em contabilidade internacional; (III) características de autoria; (IV) autores; (V) redes de coautoria; (VI) redes de coautoria (degree); (VII) IESs; (VIII) rede das IES; (IX) rede das IES (degree); (X) redes dos estados e países (degree); (XI) palavras-chave; e (XII) temas. As informações relevantes sobre cada artigo foram capturadas utilizando o software Bibexcel, e as representações gráficas das redes foram feitas usando os softwares UCINET 6 for Windows, Microsoft Excel 2007 e Wordle.net. 


\section{Análise e discussão dos resultados}

Esta seção evidencia a análise e a discussão dos 142 artigos identificados sobre o tema Contabilidade Internacional, de 1999 a 2013.

\subsection{Periódicos com publicações em Contabilidade Internacional}

A Figura 1 lista as 20 revistas que publicaram ao menos um artigo sobre Contabilidade Internacional em 15 anos de estudos.

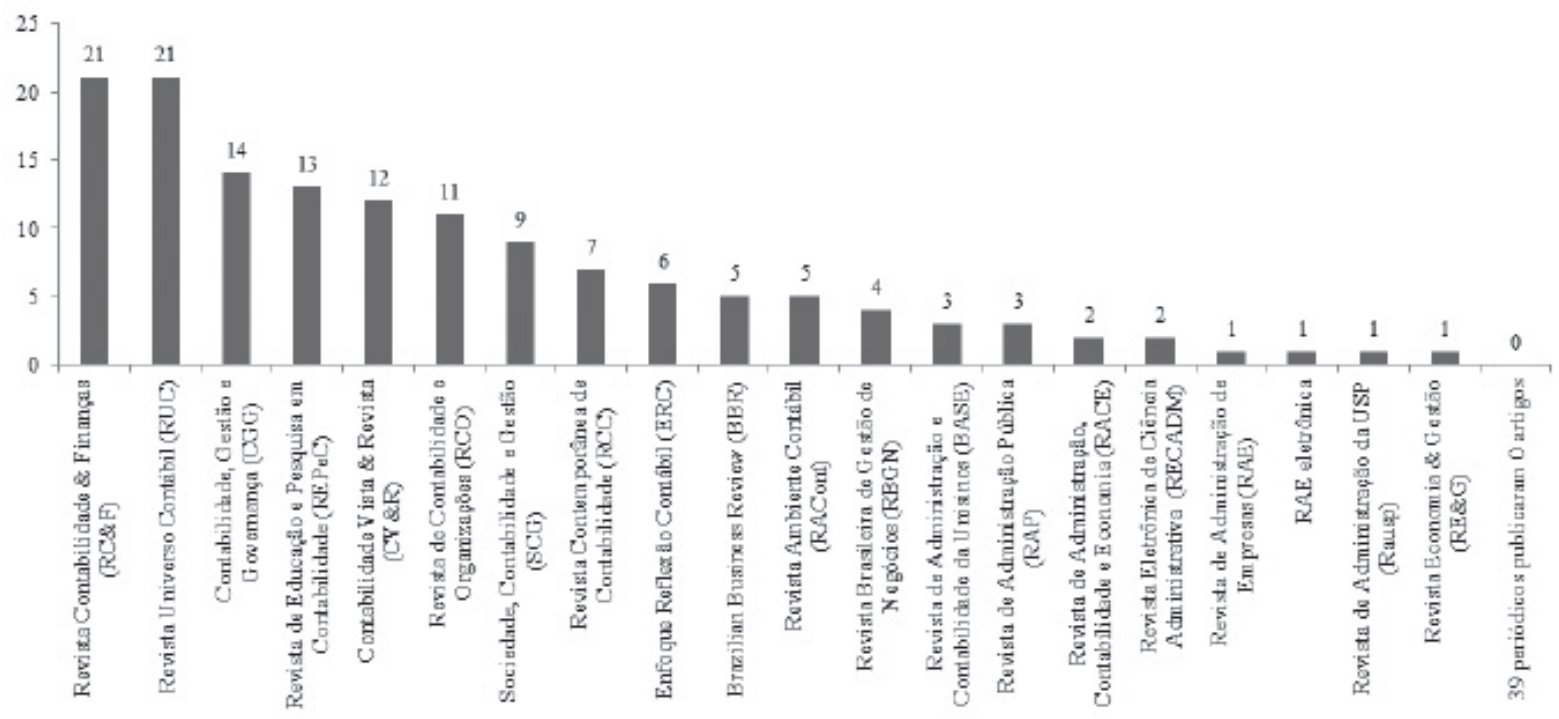

Fonte: Dados da pesquisa

Figura 1. Periódicos que publicaram artigos em Contabilidade Internacional nos últimos 15 anos

Analisando-se a Figura 1, colocam-se em evidência os periódicos: Revista Contabilidade \& Finanças e Revista Universo Contábil, pois estas foram as que se destacaram nas publicações de papers sobre Contabilidade Internacional, com 21 artigos publicados para ambas. Logo em seguida, salientam-se os periódicos: Contabilidade, Gestão e Governança, Revista de Educação e Pesquisa em Contabilidade, Contabilidade Vista \& Revista e Revista de Contabilidade e Organizações, com 14, 13, 12 e 11 artigos publicados. Os resultados realçam a importância desses periódicos para o fomento e a socialização do tema objeto de estudo, indo ao encontro da Lei de Bradford, a qual se refere à produtividade das revistas em determinado tema (Cardoso et al., 2005).

\subsection{Crescimento das publicações em Contabilidade Internacional}

A Figura 2 contempla o crescimento das publicações em Contabilidade Internacional nos periódicos analisados. 


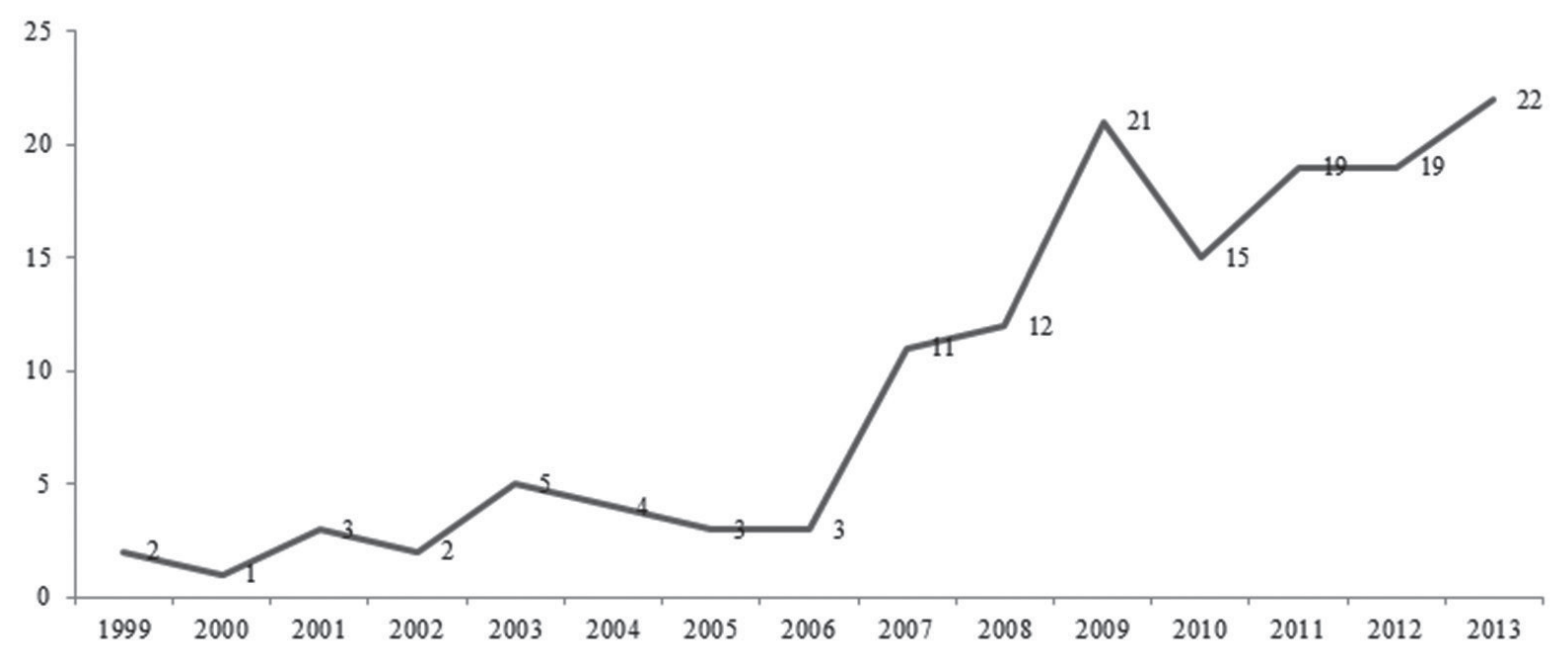

Fonte: Dados da pesquisa

Figura 2. Crescimento das publicações em contabilidade internacional

Ao se observar a Figura 2, constata-se que as publicações sobre o tema em investigação começou a crescer a partir de 2007 (com 11 artigos publicados), alcançando seu pico em 2013 (com 22 papers publicados). É interessante notar que o crescimento sobre o tema ocorreu justamente a partir do período de 2007, ano que coincide com a promulgação da Lei n. ${ }^{\circ} 11.638 / 07$. Ainda analisando a Figura 2, observa-se que, no ano de 2009, também ocorreu um destaque no número de publicações, com 21 artigos sobre o tema Contabilidade Internacional. E tal fato pode ser também em virtude da divulgação da Lei n. ${ }^{\circ} 11.941 / 09$. Realça-se que tais leis foram essenciais para o fomento do processo de harmonização realizada de forma gradativa no Brasil, conforme os padrões internacionais de contabilidade, emitindo um conjunto de normas para a fase de adoção inicial em 2008, e projetando uma fase posterior de integral convergência com as normas da IFRS em 2010.

\subsection{Perfil de autoria}

A Figura 3 visualiza o perfil das autorias dos 142 artigos publicados em 15 anos de estudos.

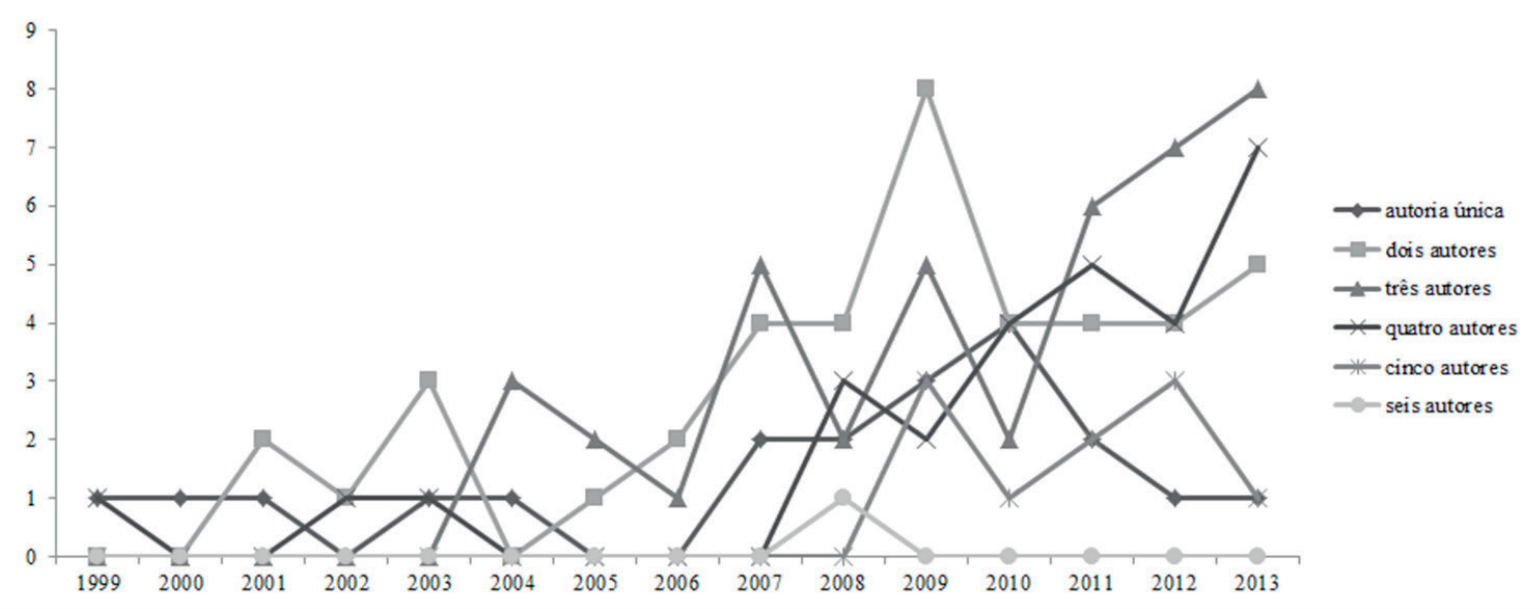

Fonte: Dados da pesquisa

Figura 3. Perfil das autorias 
Ao se verificar a Figura 3, observa-se que as publicações realizadas em parceria foram predominantes, alcançando um percentual de, aproximadamente, $86 \%$ do total dos 142 artigos identificados. Entre as parcerias, as de dois e três autores ficaram em evidencia. É salutar dizer que essas publicações em parceria, ocorrendo, principalmente, a partir do ano de 2007, promoveu, otimizou e aperfeiçoou as publicações sobre o tema objeto de estudo na literatura acadêmica nacional, por meio de antigos e novos grupos de estudos que surgiram em decorrência desse fato. Esses achados são confirmados pelos pesquisadores Quintana e Fernandes (2011).

\subsection{Perfil dos Autores}

A Figura 4 mostra os 297 autores identificados, sobretudo os oito autores mais profícuos em 15 anos de publicações em Contabilidade Internacional nos periódicos analisados.

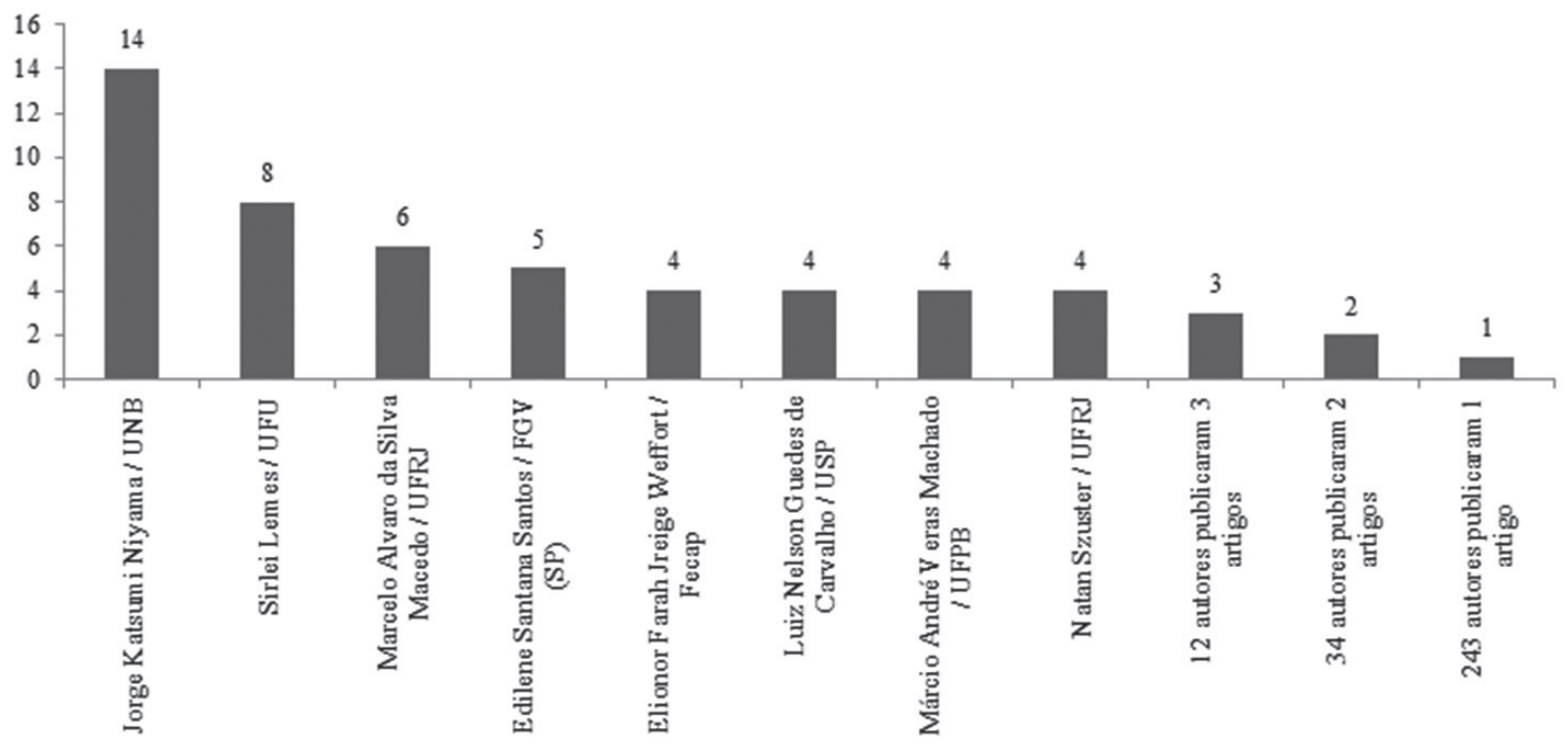

Fonte: Dados da pesquisa

Figura 4. Perfil de autoria

Analisando-se a Figura 4, realça-se o nome de Jorge Katsumi Niyama como o autor mais profícuo, publicando 14 artigos. Logo em seguida, ressaltam-se os pesquisadores: Sirlei Lemes, Marcelo Álvaro da Silva Macedo, Edilene Santana Santos e Elionor Farah Jreige Weffort, com oito, seis, cinco artigos, respectivamente; e Luiz Nelson Guedes de Carvalho, Márcio André Veras Machado e Natan Szuster, esses com quatro papers publicados.

De maneira geral, 54 autores publicaram de dois a 14 artigos, e 243 pesquisadores publicaram apenas um artigo, correspondendo a $81,82 \%$ do total dos articulistas. Esse achado vai ao encontro da Lei de Lotka, a qual enfatiza os padrões de produtividade dos autores em determinada área do conhecimento, ou seja, poucos autores publicam muito e muitos autores publicam pouco. 


\subsection{Redes de coautoria}

A Figura 5 evidencia a rede social dos 297 autores identificados neste estudo, com 297 nós e 830 laços.

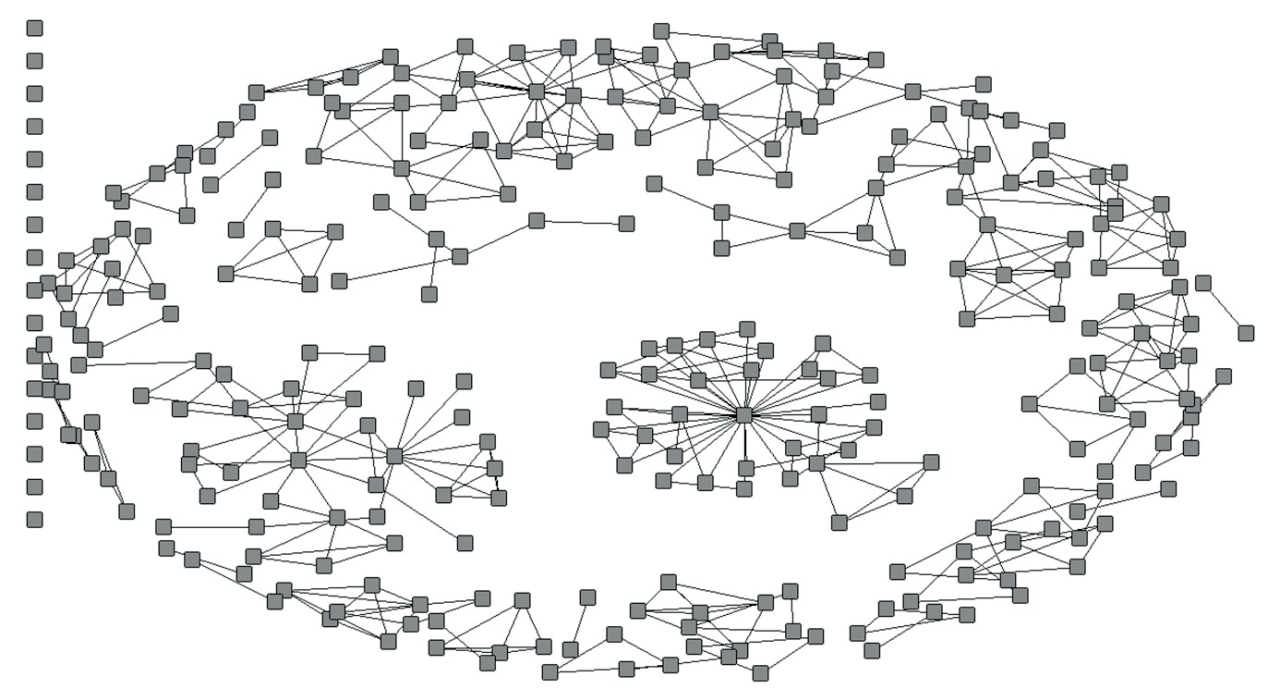

Fonte: Dados da pesquisa

Figura 5. Redes de coautoria

Ao se analisar a Figura 5, observa-se que ela é bem esparsa, refletindo em uma baixa densidade. Apenas $1,03 \%$ das interações são realizadas entre os autores. Tal resultado não é o ideal, no que tange à troca de relações em uma rede social, podendo impactar em uma centralidade de grau alta, deixando transparecer que existem poucos autores que se destacam em relação aos outros autores da rede ora investigada. Tal afirmação pode ser vista ao se analisar a Figura 6 a seguir.

\subsection{Redes de coautoria (degree)}

A Figura 6 evidencia a mesma rede social da Figura 5, contudo, colocando em evidência os autores que se destacaram por suas respectivas centralidades de grau.

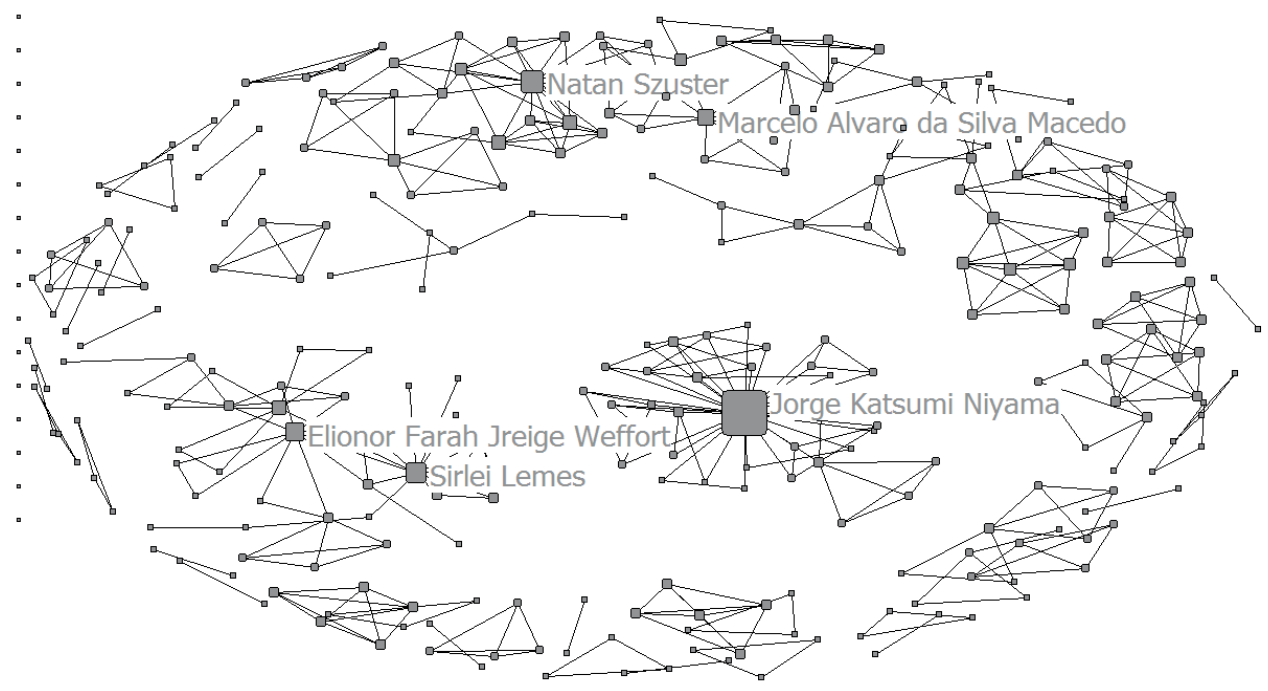

Fonte: Dados da pesquisa

Figura 6. Redes de coautoria (degree) 
Observando-se a Figura 6, nota-se que Jorge Katsumi Niyama, Sirlei Lemes, Elionor Farah Jreige Weffort, Natan Szuster e Marcelo Alvaro da Silva Macedo são os articulistas com maior centralidade de grau entre os 297 autores deste estudo. Ressalta-se que esses cinco estão entre os oito autores que mais publicaram artigos sobre Contabilidade Internacional em 15 anos de estudos nos periódicos analisados. Realça-se assim a importância e a liderança desses pesquisadores na rede social do tema em investigação.

\subsection{Perfil das publicações por IESs}

A Figura 7 evidencia as 24 IES que publicaram mais de um artigo entre as 78 identificadas neste estudo.

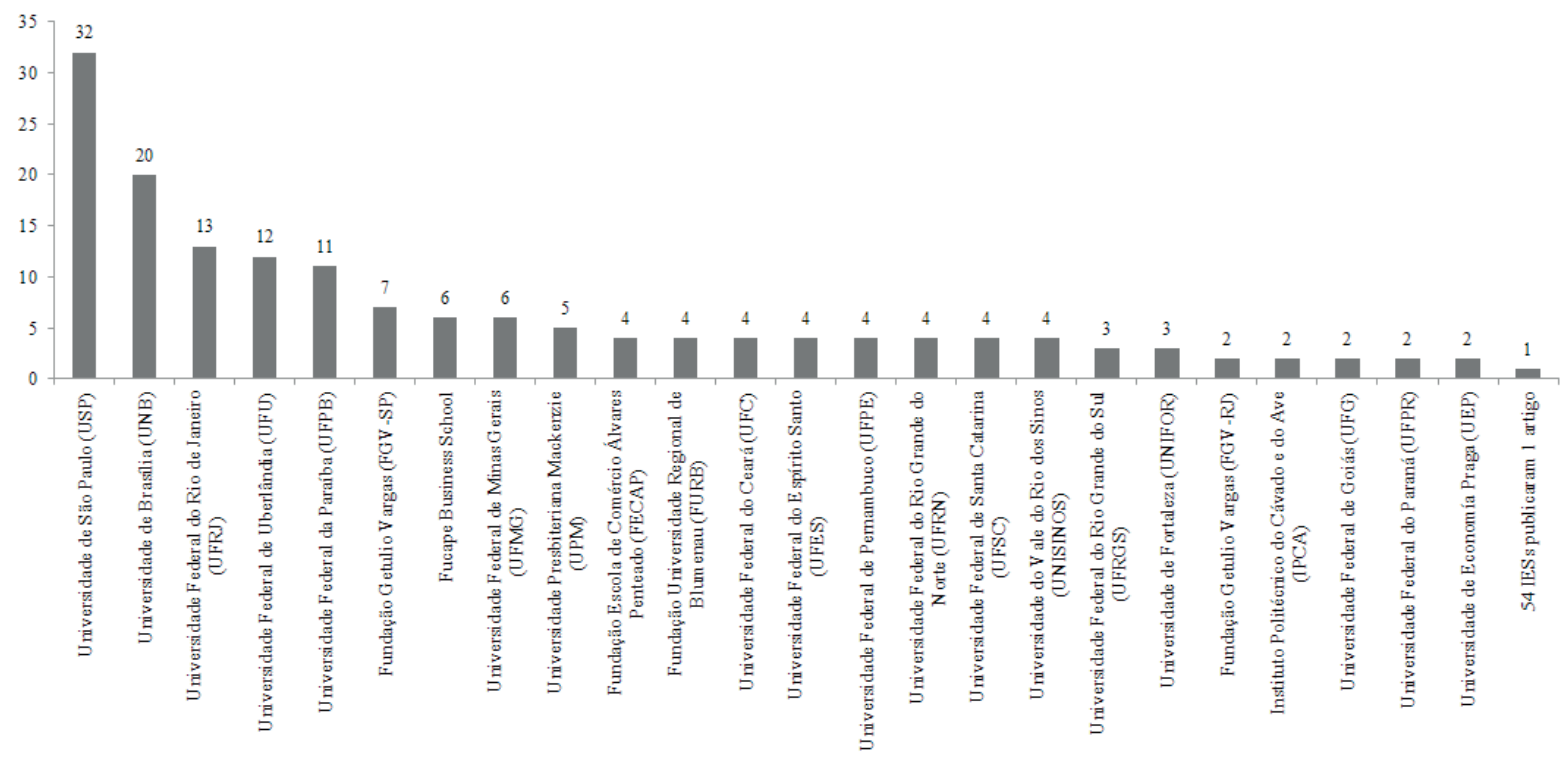

Fonte: Dados da pesquisa

Figura 7. IESs com maior número de publicações

A USP se destaca como a IES mais profícua nas publicações de estudos sobre Contabilidade Internacional nos periódicos analisados, com 32 artigos. A pesquisa dos autores Quintana e Fernandes (2011) corroboram os achados. Evidencia-se também a UnB como a segunda que mais publicou artigos, com 20 publicações. Evidenciam-se também as IES: UFRJ, UFU e UFPB, com 13, 12 e 11 artigos publicados. Das 78 IES identificadas neste estudo, 24 publicaram mais de um artigo e o restante, 54, publicou apenas uma vez. 


\subsection{Redes das IESs}

A Figura 8 realça a rede social das 78 IES identificadas neste trabalho. Tal rede representa 78 nós e 124 laços.

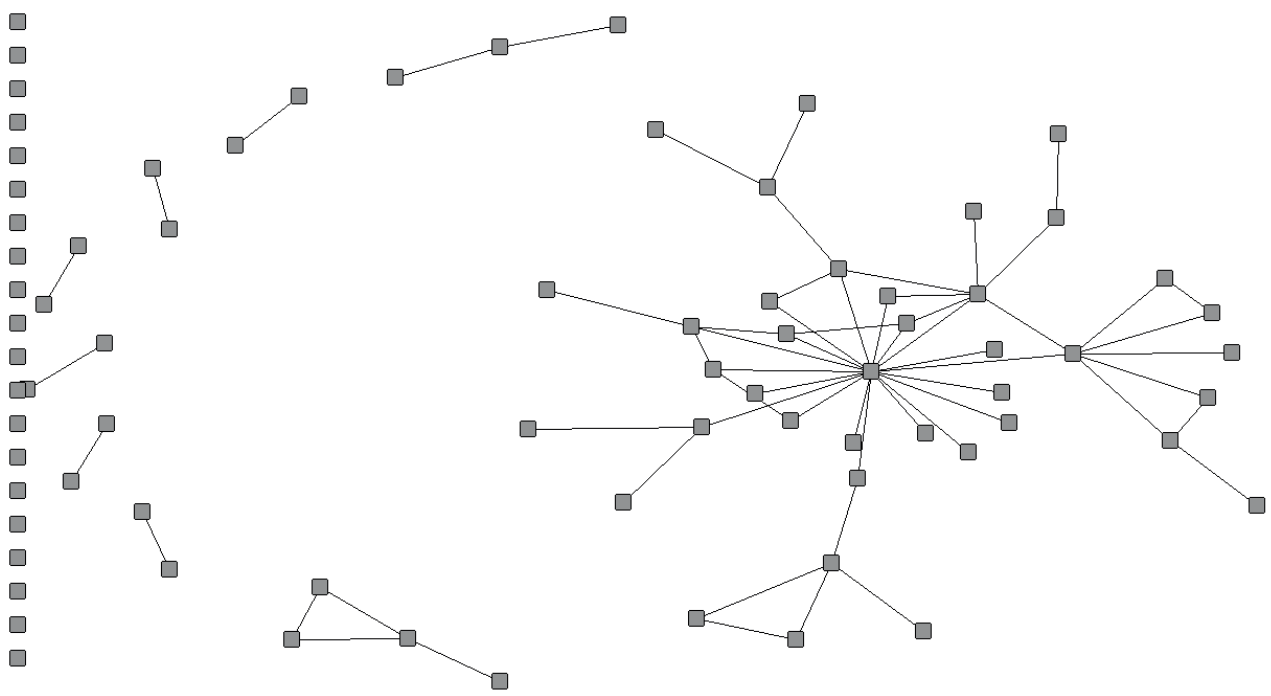

Fonte: Dados da pesquisa

Figura 8. Redes das IESS

Observando-se a Figura 8, nota-se que 20 IES publicaram sozinhas; 19 IES publicaram em oito grupos de estudos distintos; e 39 IES estão conectadas de maneira direta ou indireta entre si em um grupo de pesquisa maior que se visualiza no lado direito da Figura 8. Ainda é interessante salientar que a referida rede encontra-se dispersa, impactando em uma baixa densidade, de 0,0273.

\subsection{Redes das IESs (degree)}

A Figura 9 contempla a rede social das IES, enfatizando as com maior centralidade de grau.

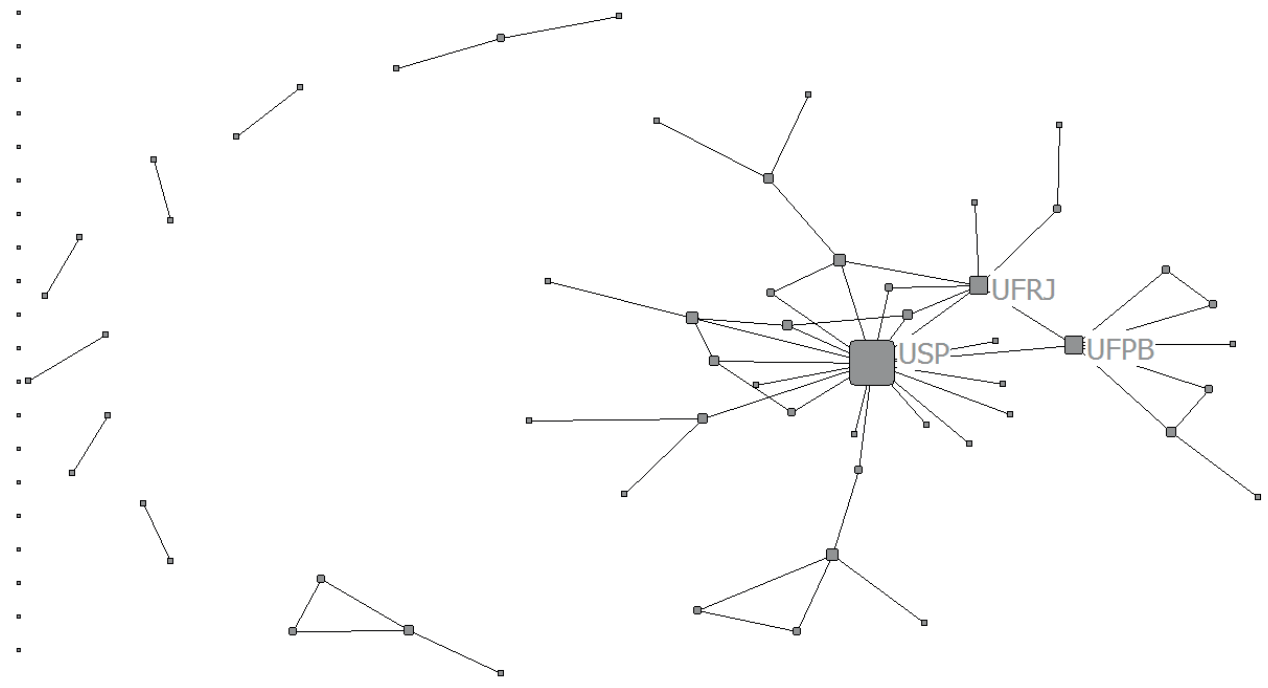

Fonte: Dados da pesquisa

Figura 9. Redes das IES (Degree) 
Ao se analisar a Figura 9, constata-se que as IES: USP, UFRJ e UFPB foram as que apresentaram maior centralidade de grau. Essas três IES realçadas estão entre as cinco com maior proficuidade (Figura 7). É interessante notar que essas três instituições que se destacaram nesta seção compõem a maior rede de instituições que se sobressaem dentre as demais.

\subsection{Redes dos estados e países (degree)}

A Figura 10 realça as redes sociais entre os 16 estados e as nove nações envolvidas e identificadas neste estudo. Ressalta-se que essa rede coloca em evidência a centralidade de grau.

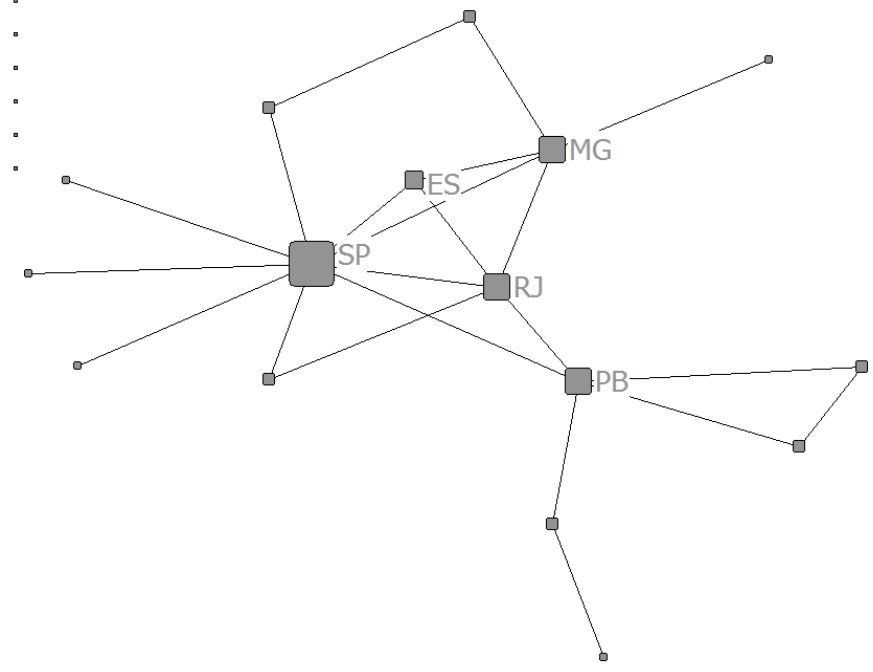

Fonte: Dados da pesquisa

Figura 10. Redes dos estados e países (Degree)

Ao se verificar a Figura 10, ressaltam-se os estados de São Paulo, Minas Gerais, Paraíba, Rio de Janeiro e Espirito Santo. E são desses estados as primeiras 10 IES que mais publicaram artigos sobre o tema em análise. O estudo de Botelho (2012) corrobora com os achados contemplados nesta seção. 


\subsection{Palavras-chave}

Já a Figura 11 realça a nuvem de palavras-chave retiradas dos 142 artigos identificados e investigados neste estudo.

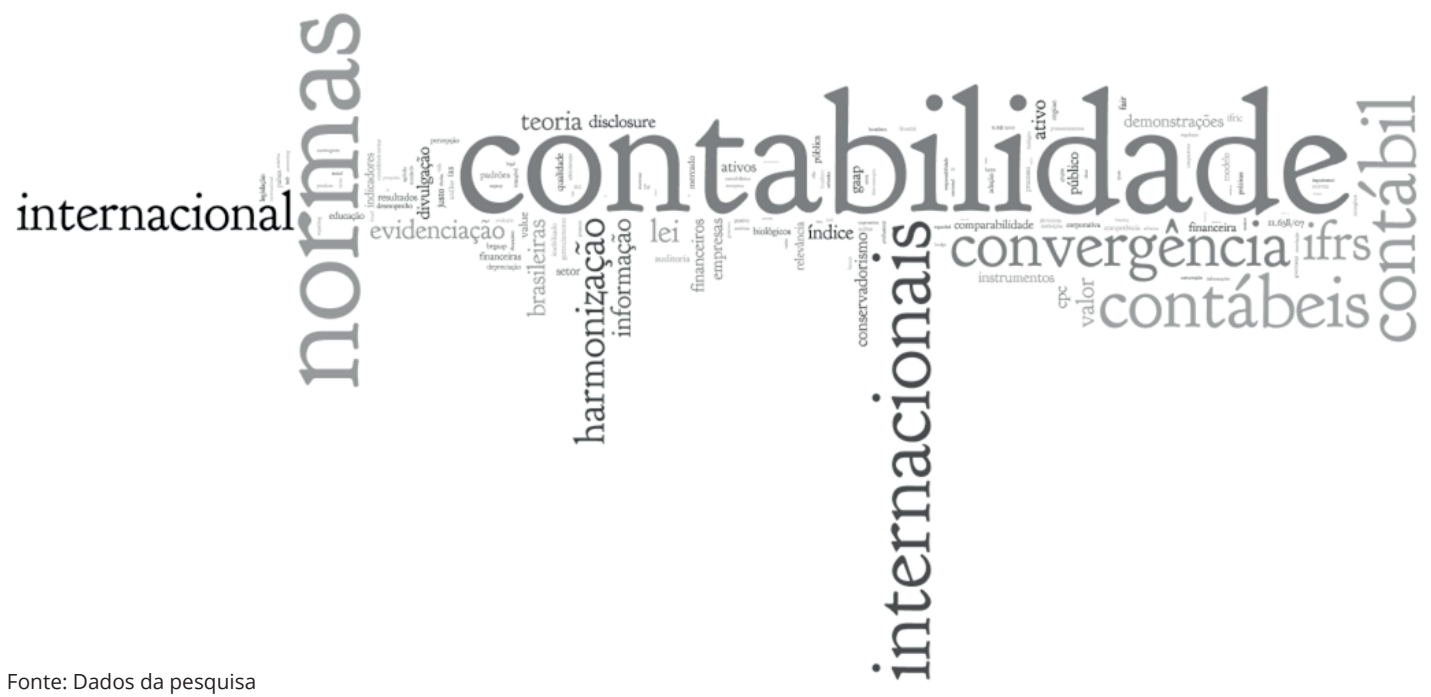

Figura 11. Palavras-chave

Ao se observar a Figura 11, realçam-se, dentre outras, as palavras-chave: contabilidade, normas, internacionais, internacional, convergência, contábeis, contábil, harmonização. Tal resultado é essencial para se saber quais temas foram mais abordados em consonância com a Lei de Zipf.

\subsection{Temas}

A Figura 12 destaca os 22 temas entre os 47 identificados e que têm relação com o assunto Contabilidade Internacional. A ênfase se deve ao fato de esses 22 temas serem aqueles que foram publicados, no mínimo, três vezes durante os 15 anos analisados neste estudo.

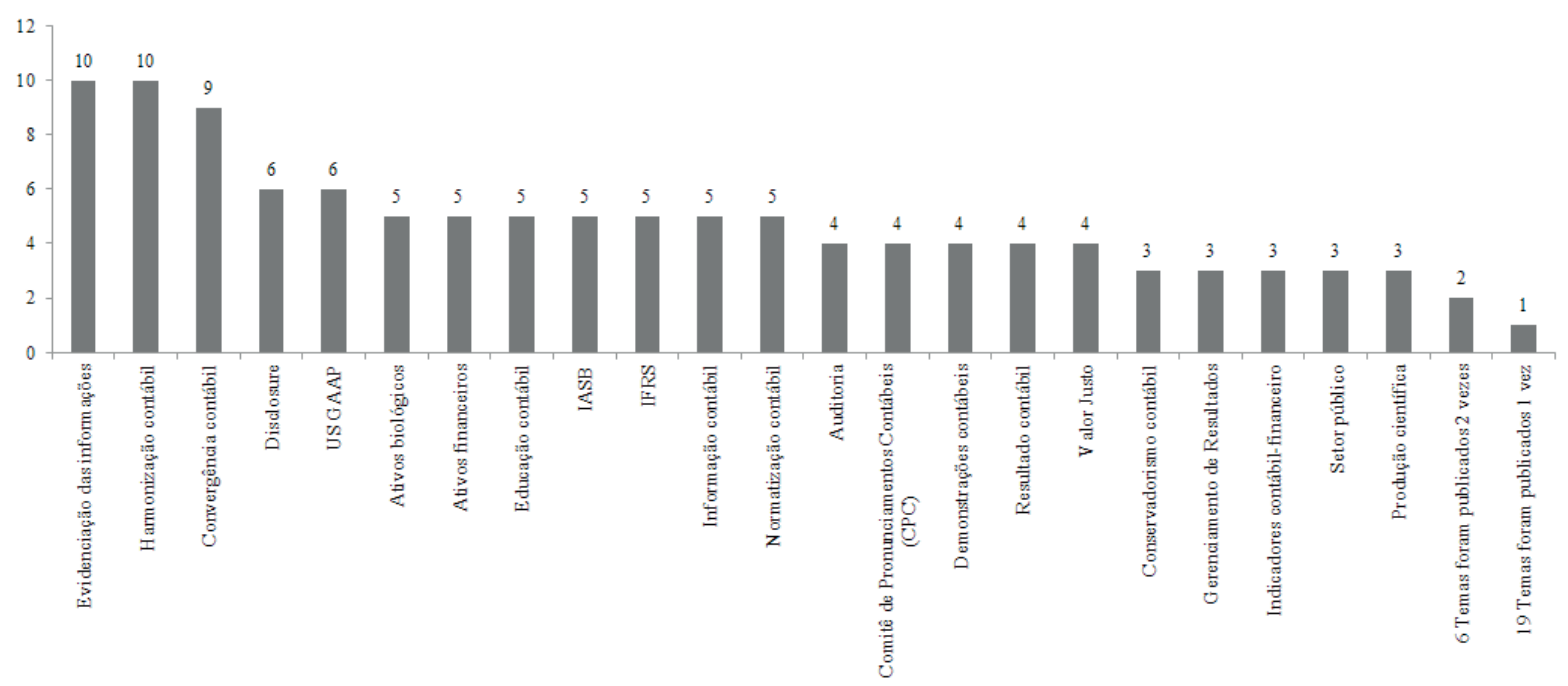

Fonte: Dados da pesquisa

Figura 12. Temas 
Analisando-se a Figura 12, enfatizam-se os temas evidenciação das informações e harmonização contábil como os que mais foram publicados no período, com 10 artigos para ambos. Pode-se entender que é ponto fundamental para a Contabilidade Internacional a evidenciação das informações de maneira transparente e a harmonização contábil (Vaz et al., 2010). Em seguida, realça-se a convergência contábil, que apareceu como temática principal em nove papers. Entende-se que a convergência contábil é importante por ser um processo de normas que buscam atingir um estado de harmonização contábil formal (Lemes \& Carvalho, 2009).

Já os assuntos disclosure e US-GAAP foram publicados (ambos) seis vezes. Ressaltam-se esses temas como preponderantes para a evidenciação contábil, pois os US-GAAP realçam a importância do disclosure na harmonização e convergência de suas normas no cenário mundial (Oliveira \& Lemes, 2011).

Outros temas que se destacaram neste estudo foram: ativos biológicos, ativos financeiros, educação contábil, Iasb, IFRS, informação contábil e normatização contábil, todos com cinco artigos publicados. Destes, realçam-se os assuntos IFRS, Iasb e normatização contábil. Diante do exposto, evidencia-se a forte relação entre as três temáticas, devido à normatização contábil de as IFRS serem emitidas pelo Iasb.

Com quatro artigos publicados, apareceram os temas: Auditoria, Comitê de Pronunciamentos Contábeis (CPC), Demonstrações Contábeis, Resultado Contábil e Valor Justo. E com três artigos estão os assuntos: Conservadorismo Contábil, Gerenciamento de Resultados, Indicadores Contábil-Financeiro, Setor Público e Produção Científica. Salienta-se também que seis assuntos foram publicados duas vezes cada, 19 temáticas apareceram como tema principal e publicações de Contabilidade Internacional, uma vez somente. Dentre elas, pode-se destacar: Ativo Diferido, Ativos Intangíveis, Controladoria, Estratégia e Profissão Contábil.

\section{Considerações finais}

Este artigo investigou o perfil e o crescimento, no período de 1999 a 2013, das publicações acadêmicas sobre Contabilidade Internacional em periódicos brasileiros classificados com notas A1, A2, B1 e B2, pela Qualis/Capes das áreas de Administração, Contabilidade e Turismo (triênio 2010-2012). Para isso, foram utilizadas as técnicas de análise bibliométrica e de rede social em 142 artigos identificados, publicados em 59 periódicos.

Este artigo contribui para o esforço de fomento, disseminação, divulgação e aperfeiçoamento do tema Contabilidade Internacional para a literatura acadêmica nacional, proporcionando assim o surgimento ou agregação de possíveis novos pesquisadores, acarretando na criação ou robustez de grupos de estudos, contribuindo a posteriori para uma maior condensação das redes do conhecimento sobre o assunto. Diante disso, contribuirá e incentivará o maior crescimento da temática, pois ela será mais otimizada, evidenciada e socializada por meio de artigos acadêmicos, de anais de eventos e periódicos nacionais e internacionais, gerando valor na estrutura intelectual de seu conhecimento.

Dentre os principais resultados, observou-se que a Revista Contabilidade \& Finanças e a Revista Universo Contábil foram os periódicos analisados que mais publicaram artigos sobre Contabilidade Internacional em 15 anos de estudos. O tema começou a evoluir, em especial no período de 2007, alcançando seu ápice em 2013. Houve predominância de estudos em parceria, sobretudo, com dois e três autores. Desses autores, Jorge Katsumi Niyama foi o que mais publicou na área - 14 artigos no total. Niyama também se destacou como o pesquisador mais central dentre os 297 articulistas identificados. Contudo, a rede de coautoria teve uma baixa densidade, sendo também observada essa baixa densidade na rede das IES, onde, verificou-se a alta centralidade de grau das IES, USP, UFRJ e UFPB. E essas também se encontram entre as cinco com maior produção acadêmica sobre o tema ora em investigação, junto com a UnB e UFU. Dentre as cinco IES com maior produção, constata-se que elas são oriundas dos estados de São Paulo, Rio de Janeiro, Paraíba, Distrito Federal e Minas Gerais. E desses cinco estados, quatro destacam-se por suas respectivas centralidades de grau. São eles: São Paulo, Rio de Janeiro, Paraíba e Minas Gerais. 
No que se refere aos temas, este estudo identificou 47, entre estes, 19 só foram publicados uma única vez. E os cinco mais presentes foram: evidenciação das informações, harmonização contábil, convergência contábil, disclosure e US GAAP.

Este estudo limitou-se em estudar apenas o extrato das revistas A2, B1 e B2, com isso, seria importante ampliar esse extrato, ou seja, agregando os periódicos B3, B4 e B5 do Qualis/Capes (triênio 20102012). Outra limitação do estudo foi a quantidade de anos analisada, ou seja, 15 (1999 a 2013). Diante do fato, seria também conveniente ampliar a quantidade de anos de estudo. Sugere-se também uma análise de conteúdo dos 47 temas identificados, proporcionando assim um melhor entedimento deles, sobretudo, daqueles temas que foram publicados em quantidade menor. Sugere-se também, aperfeiçoar as técnicas de análise de rede, focando as centralidades de aproximação e intermediação também. Outra sugestão é a utilização da estatística multivariada de dados.

\section{Referências}

Botelho, D. R. (2012). Epistemologia da pesquisa em contabilidade internacional: enfoque cultural-reflexivo. $174 \mathrm{f}$. Tese de Doutorado em Ciências Contábeis - Universidade de Brasília - UNB, Brasília, DF, Brasil.

Botelho, D. R., Oliveira, J. L., Resende, A. L., \& Ogliari, P. R. (2002). Importância da harmonização das normas e procedimentos contábeis internacionais. In: Associação Nacional de Pós-Graduação e Pesquisa em Administração, XXVI., 2002, Salvador. Anais Eletrônicos... São Paulo: EnANPAD. Recuperado em 10 dezembro, 2013, de < http://www.anpad.org.br/>.

CAPES - Coordenação de Aperfeiçoamento de Pessoal de Nível Superior (2014). Webqualis. Recuperado em 10 dezembro, 2013, de <http://qualis.capes.gov.br/webqualis/principal.seam>.

Cardoso, R. L., Mendonça Neto, O. R., Riccio, E. L., \& Sakata, M. C. G. (2005). Pesquisa científica em contabilidade entre 1990 e 2003. Revista de Administração de Empresas, 45(2), pp. 34-45.

Carmo, C. H. S., Ribeiro, A. M., \& Carvalho, L. N. G. (2011). Convergência de fato ou de direito? A influência do sistema jurídico na aceitação das normas internacionais para pequenas e médias empresas. Revista Contabilidade \& Finanças, 22(57), pp. 242-262.

Coelho, C. M. P., Niyama, J. K., \& Rodrigues, J. M. (2011). Análise da qualidade da informação contábil frente a implementação dos IFRS: uma pesquisa baseada nos periódicos internacionais (1999 a 2010). Sociedade, Contabilidade e Gestão, 6(2), pp. 7-20.

Cruz, A. P. C., Espejo, M. M. S. B., Costa, F., \& Almeida, L. B.. (2011). Perfil das redes de cooperação científica: Congresso USP de Controladoria e Contabilidade - 2001 a 2009. Revista Contabilidade \& Finanças, 22(55), pp. 64-87.

Cunha, P. R., Rausch, R. B., \& Cunha, J. V. A. (2010). Contabilidade internacional: uma análise metodológica e técnica das pesquisas publicadas no Congresso USP de Controladoria e Contabilidade e na Revista de Contabilidade \& Finanças da USP. Contabilidade, Gestão e Governança, 13(3), pp. 116-131.

De Luca, M. M. M., Gomes, C. A. S., Corrêa, D. M. M. C., \& Domingos, S. R. M. (2011). Participação feminina na produção científica em contabilidade publicada nos anais dos eventos Enanpad, Congresso USP de Controladoria e Contabilidade e Congresso Anpcont. Revista de Contabilidade e Organizações, 5(11), pp. 145-164.

Egghe, L. (2005). Zipfian and lotkaian continuous concentration theory. Journal of the American Society for Information Science and Technology, 56(9), pp. 935-945.

Guimarães, T. A., Gomes, A. O., Odelius, C. C., Zancan, C., \& Corradi, A. A. (2009). A rede de programas de pós-graduação em administração no Brasil: análise de relações acadêmicas e atributos de programas. Revista de Administração Contemporânea, 13(4), pp. 564-582. 
Hajj, Z. S. E., \& Lisboa, L. P. (2001). Business combinations e consolidação das demonstrações contábeis: uma abordagem comparativa entre os pronunciamentos e normas dos US-GAAP, IASC e Brasil. Revista Contabilidade \& Finanças, 12(27), pp. 33-58.

Ikuno, L. M., Niyama, J. K., Santana, C. M., \& Botelho, D. R. (2012). Contabilidade internacional: uma análise da produção científica nos principais periódicos internacionais da área -2000 a 2009. Revista de Contabilidade e Organizações, 6(15), pp. 142-163.

Ikuno, L. M. (2011). Uma análise bibliométrica e epistemológica das pesquisas em contabilidade internacional: um estudo em periódicos internacionais de língua inglesa. 135 f. Dissertação de Mestrado em Ciências Contábeis - Universidade de Brasília - UNB, Brasília, DF, Brasil.

Lei $n^{\circ} 11.638$, de 28 de dezembro de 2007. Altera e revoga dispositivos da Lei no 6.404, de 15 de dezembro de 1976, e da Lei no 6.385, de 7 de dezembro de 1976, e estende às sociedades de grande porte disposições relativas à elaboração e divulgação de demonstrações financeiras. Diário Oficial da União. Brasília, DF: Casa Civil.

Lei $n^{\circ} 11.941$, de 27 de maio de 2009. Altera a legislação tributária federal relativa ao parcelamento ordinário de débitos tributários; concede remissão nos casos em que especifica; institui regime tributário de transição, alterando o Decreto $\mathrm{n}^{\circ} 70.235$, de 6 de março de 1972, as Leis $n^{\circ}$ s 8.212, de 24 de julho de 1991, e dá outras providências. Diário Oficial da União. Brasília, DF: Casa Civil.

Leite Filho, G. A. (2008). Padrões de produtividade de autores em periódicos e congressos na área de contabilidade no Brasil: um estudo bibliométrico. Revista de Administração Contemporânea, 12(2), pp. 533-554.

Lemes, S., \& Carvalho, L. N. G. (2009). Comparabilidade entre o resultado em BR GAAP e U.S. GAAP: evidências das companhias brasileiras listadas nas bolsas norte-americanas. Revista Contabilidade \& Finanças, 20(50), pp. 25-45.

Miranda, G. J., Santos, L. A. A., Casa Nova, S. P. C., \& Cornacchione Júnior, E. B. (2013). A pesquisa em educação contábil: produção científica e preferências de doutores no período de 2005 a 2009. Revista Contabilidade \& Finanças, 24(61), pp. 75-88.

Nascimento, S. \& Beuren, I. M. (2011). Redes sociais na produção científica dos programas de pós-graduação de ciências contábeis do Brasil. Revista de Administração Contemporânea, 15(1), pp. 47-66.

Niyama, J. K., Botelho, D. R., Corrêa, B. M., \& Santana, C. M. (2008). Conhecimento de Contabilidade Internacional nos cursos de graduação em ciências contábeis: estudo da oferta nas instituições de ensino superior das capitais brasileiras. Revista de Contabilidade e Organizações, 2(2), pp. 100-117.

Niyama, J. K., Mendonça, A. C. S., \& Aquino, D. L. R. B. (2007). Estudo empírico da percepção dos alunos de graduação em ciências contábeis do Distrito Federal quanto às causas das diferenças internacionais no financial reporting das empresas. Revista Universo Contábil, 3(2), pp. 22-38.

Oliveira, V. A., \& Lemes, S. (2011). Nível de convergência dos princípios contábeis brasileiros e norte-americanos às normas do IASB: uma contribuição para a adoção das IFRS por empresas brasileiras. Revista Contabilidade \& Finanças, 22(56), pp. 155-173.

Ponte, V. M. R., De Luca, M. M. M., Sousa, H. V. \& Cavalcante, D. S. (2011). Práticas de divulgação do teste de redução ao valor recuperável de ativos pelas companhias abertas listadas na BM\&F Bovespa. Revista Contabilidade Vista \& Revista, 22(4), pp. 113-144.

Quintana, A. C., \& Fernandes, D. C. C. (2011). Produção científica sobre harmonização contábil internacional: um estudo bibliométrico na Revista Contabilidade \& Finanças da Universidade de São Paulo, no período de 2005 a 2011. In: Seminário em Administração, 14., 2011, São Paulo. Anais Eletrônicos... São Paulo: Semead. Recuperado em 10 dezembro, 2013, de <http://www.ead.fea.usp. $\mathrm{br} / \mathrm{semead} / 14 \mathrm{semead} / \mathrm{resultado} /$ trabalhosPDF/120.pdf $>$. 
Santos, E. S., \& Calixto, L. (2010). Impactos do início da harmonização contábil internacional (Lei 11.638/07) nos resultados das empresas abertas. RAE eletrônica, 9(1).

Santos, L. P. G., Lima, G. A. S. F., Freitas, S. C., \& Lima, I. S. (2011). Efeito da Lei 11.638/07 sobre o conservadorismo condicional das empresas listadas BM\&F Bovespa. Revista Contabilidade \& Finanças, 22(56), pp. 174-188.

Silva, C. B. A., Madeira, G. J., \& Assis, J. L. F. (2004). Harmonização de normas contábeis: um estudo sobre as divergências entre normas contábeis internacionais e seus reflexos na contabilidade brasileira. Revista Contemporânea de Contabilidade, 1(1), pp. 115-139.

Squena, R., \& Pasuch, D. F. (2010). Goodwill: sua definição e relevância para a área contábil. Revista Gestão Organizacional, 3(1), pp. 44-57.

Ribeiro, H. C. M. (2013a). Características da produção veiculada na Revista de Educação e Pesquisa em Contabilidade no período de 2007 a 2012. Revista de Educação e Pesquisa em Contabilidade, 7(4), pp. 424-443.

Ribeiro, H. C. M. (2013b). Revista Contemporânea de Contabilidade: uma análise do perfil da produção acadêmica durante o período de 2004 a 2012. Revista Contemporânea de Contabilidade, 10(20), pp. 03-28.

Rossoni, L., \& Guarido Filho, E. R. (2009). Cooperação entre programas de pós-graduação em administração no Brasil: evidências estruturais em quatro áreas temáticas. Revista de Administração Contemporânea, 13(3), pp. 366-390.

Tavares, M. F. N., Lopes, J. E. G., \& Ribeiro Filho, J. F.; Pederneiras, M. M. M.; Amaro, R. G.; Iudícibus, S. de. (2010). Uma contribuição epistemológica à contabilidade internacional: análise nas dissertações e teses brasileiras divulgadas no banco de dados de teses e dissertações (BDTD) entre 1999 e 2008. Advances in Scientific and Applied Accounting, 3(2), pp. 217-238.

Vaz, A. C., Gonçalves, R. S., Niyama, J. K., \& Gonçalves, A. O. (2010). Análise comparativa sobre informações voluntárias divulgadas: o social disclosure das empresas latino-americanas listadas na NYSE. Revista de Educação e Pesquisa em Contabilidade, 4(1), pp. 38-59. 